\title{
RISCO CLIMÁTICO PARA O CULTIVO DO ALGODOEIRO NA REGIÃO NORDESTE DO BRASIL
}

\section{PEDRO VIEIRA DE AZEVEDO e FABRÍCIO DANIEL DOS SANTOS SILVA}

\author{
Universidade Federal de Campina Grande (UACA), Centro de Tecnologia e Recursos Naturais (CTRN), \\ Unidade Acadêmica de Ciências Atmosféricas (UFCG). \\ Av. Aprígio Veloso, 882, Bodocongó, 58109-970, Campina Grande-PB, \\ E-mail: pvieira@dca.ufcg.edu.br
}

Recebido Setembro 2006 - Aceito Novembro 2006

\begin{abstract}
RESUMO
Médias semanais de radiação solar, precipitação pluviométrica, evapotranspiração e temperatura do ar foram utilizadas na delimitação das áreas da região Nordeste do Brasil com menor risco climático para o cultivo do algodão. Para cultivos irrigados, o potencial de rendimento da cultura foi avaliado pelo índice acumulado de crescimento (IAC). Para cultivo de sequeiro, o risco climático foi determinado pelo déficit potencial de água (DPA). Para cultivos irrigados, o menor risco de queda de produtividade ocorre quando o algodoeiro é semeado de 6 a 19 de agosto. Para cultivos de sequeiro, o menor risco climático é alcançado para semeaduras desde a $44^{\mathrm{a}}$ (região Oeste da Bahia) à $19^{\mathrm{a}}$ semana do ano. A partir da $1^{a}$ semana do ano, as condições favoráveis à semeadura iniciam-se na região Central do Piauí, atingindo o máximo de aptidão no período entre a $4^{\mathrm{a}}$ e a $8^{\mathrm{a}}$ semana do ano, na maior parte dos estados do Piauí, Rio Grande do Norte, Paraíba, Pernambuco e Norte da Bahia. Nas regiões Sul e Oeste da Bahia, o menor risco climático é alcançado com a semeadura na $10^{\mathrm{a}}$ e $46^{\mathrm{a}}$ semanas do ano, respectivamente. $\mathrm{Na}$ Costa Leste, o plantio do algodoeiro é mais favorável no período compreendido entre a $14^{\mathrm{a}}$ e a $17^{\mathrm{a}}$ semana do ano, cobrindo as áreas litorâneas do Rio Grande do Norte ao Norte do estado da Bahia e quase que totalmente os estados de Alagoas e Sergipe.

Palavras-chave: Cultivo de sequeiro e cultivo irrigado, índice acumulado de crescimento, déficit potencial de água.
\end{abstract}

\begin{abstract}
CLIMATIC RISK FOR COTTON CROP GROWTH IN NORTHEAST REGION, BRAZIL.

Weekly mean values of solar radiation, rainfall, evapotranspiration and air temperature were used for establishing the lower climatic risk to the cotton crop. For irrigated fields, the potential crop yield was evaluated by the cumulative growth index (CGI), while for rain-fed conditions the climatic risk was determined by the water potential deficit (WPD). Under irrigated and rain-fed conditions, the lower climatic risk occurs when cotton crop is sowing from 6 to 19 August and from the $44^{\text {th }}$ (West region of Bahia state) to the $19^{\text {th }}$ week of the year. From the $1^{\text {st }}$ week of the year, the most suitable date for cotton sowing start in the Central region of Piauí state, reaching maximum covering area of Piauí, Rio Grande do Norte, Paraíba, Pernambuco states and North of Bahia state in the period between the $4^{\text {th }}$ and the $8^{\text {th }}$ week. In the South and West regions of Bahia state, the lower climatic risk is reached by cotton crop when sowing in the $10^{\text {th }}$ and $46^{\text {th }}$ weeks. In the northeast Coast, otherwise the cotton crop sowing is more suitable in the period from the $14^{\text {th }}$ to $17^{\text {th }}$ week, covering most of the coastal shore table lands from Rio Grande do Norte to Bahia states and almost the total areas of the Alagoas and Sergipe states.
\end{abstract}

Keywords: Rain-fed and irrigated cropping, cumulative growth index, water potential deficit. 


\section{INTRODUÇÃO}

O zoneamento do risco climático da atividade agrícola constitui-se numa ferramenta de fundamental importância para o planejamento da agricultura, o qual deve ser constantemente atualizado com a utilização de banco de dados cada vez mais completos e consistentes, visando a melhor definição dos limites climáticos para o atendimento à adaptabilidade de novas variedades (Sediyama et al., 2001). Portanto, tal zoneamento basea-se na delimitação das regiões com condições edafoclimáticas homogêneas para o desenvolvimento de atividades agrícolas e gerenciamento dos recursos naturais nela existentes (Bastos \& Azevedo, 1986; Santos, 1999). Segundo Gargantini \& Hernandez (2003), 25\% da economia brasileira provêm da agroindústria e o agro-negócio é responsável por 37\% da mão-de-obra empregada. A economia globalizada exige que a agricultura se adapte às novas exigências e complexidades do mercado externo, o que pode ser alcançado através de um sistema gerencial com o melhor aproveitamento possível dos recursos produtivos.

A produção agrícola da região Nordeste do Brasil tem sido fortemente afetada pelos efeitos das freqüentes e longas estiagens ocorridas, principalmente no chamado "Polígono das secas", tornando a atividade agrícola nessa região primordialmente de subsistência. Resta, como principal alternativa, o aproveitamento das áreas com maior potencial agrícola, do ponto de vista de água e solo, com a exploração racional dos recursos hídricos e edáficos disponíveis, através da exploração das culturas economicamente mais rentáveis. Assim, tanto na agricultura irrigada quanto de sequeiro, necessário se faz que os recursos naturais disponíveis na região sejam usados de forma racional, através da utilização de técnicas apropriadas de manejo da água, do solo e do plantio e/ou semeadura (Chaves et al., 1982). O conhecimento do regime de chuvas, associado ao monitoramento da umidade do solo permite o estabelecimento do início, duração e término da estação chuvosa de determinada região. Tal conhecimento permite também, a determinação da estação de cultivo, época de plantio/semeadura com menor risco climático e a elaboração do calendário agrícola, tanto para a agricultura de sequeiro quanto para projetos de irrigação.

No caso do algodão, mais de $60 \%$ das áreas mundiais cultivadas são irrigadas. Os países que apresentam as maiores produtividades como Israel, Austrália, Peru, Estados Unidos, México e Egito irrigam totalmente a área plantada ou parte dela (Federacion Nacional de Algodoneros, 1990). Entre todas as culturas irrigadas no mundo, o algodoeiro corresponde a $7 \%$ de toda a área explorada com esse tipo de cultivo (World Bank, 1990). Isto ocorre devido à importância de sua fibra na fabricação de tecidos para vestimenta de aproximadamente $50 \%$ da população mundial (Barreto et al., 1994). A região semi-árida do Nordeste do Brasil apresenta condições climáticas favoráveis à cotonicultura, já que o algodão necessita de temperaturas ambientais na faixa de 18 a $30^{\circ} \mathrm{C}$, elevadas radiação solar e insolação. Acrescente-se a isto, a existência de cultivares de ciclo (da emergência a primeira colheita) curto (100 - 120 dias) e médio (130 - 150 dias), que consomem entre 450 e 700 $\mathrm{mm}$ de água e apresentam potencial de rendimento superior a $3.000 \mathrm{~kg} / \mathrm{ha}$ de algodão em caroço (Amorim Neto \& Beltrão, 1992). Nessa região, o algodão é cultivado predominantemente em condições de sequeiro, em que a estação de cultivo, a qual deve coincidir com a estação chuvosa, nem sempre é adequada e suficientemente longa para suprir as necessidades hídricas da cultura em todos os seus sub-períodos de desenvolvimento (Azevedo \& Maciel, 1993; Steenkamp \& Kock, 1996). Para minimizar tais efeitos adversos, deve-se ajustar a época de semeadura dentro da estação chuvosa, de tal forma que haja umidade no solo suficiente para a germinação, evitando-se excesso de umidade nos sub-períodos de abertura dos capulhos e da colheita do algodão em caroço, o que poderá aumentar substancialmente a produtividade do algodoeiro (Fallieri \& Silva, 1968; Laca-Buendia et al., 1997).

O presente trabalho objetivou a delimitação das áreas da região Nordeste do Brasil com aptidões edafoclimáticas para o cultivo do algodão herbáceo, estabelecendo-se os riscos climáticos de cada área e do período de cultivo.

\section{MATERIAL E MÉTODOS}

As séries de dados de precipitação pluviométrica (Pr), radiação solar (Rs) e temperatura do ar (Ta) para os municípios da região Nordeste do Brasil, disponíveis no Banco de Dados da Unidade Acadêmica de Ciências Atmosféricas (UACA/CTRN/ UFCG) foram utilizadas na determinação das áreas com aptidão edafoclimática para o cultivo do algodão herbáceo sob condições de irrigação e de sequeiro.

\section{a) Cultivos irrigados}

Em áreas irrigadas, o potencial energético constitui-se como o fator limitante do crescimento e desenvolvimento das plantas cultivadas. Neste caso, o risco climático para qualquer cultura e época de semeadura é determinado com base no coeficiente foto-térmico (CF). No caso do algodoeiro herbáceo (Gossypium hirsutum r. latifolium), o CF semanal foi definido como (Azevedo \& Maciel (1993) e Azevedo et al. , 2004):

$$
(\mathrm{CF})_{\mathrm{j}}=\mathrm{Rs}_{\mathrm{j}} /\left(\mathrm{Ta}_{\mathrm{j}}-\mathrm{T}_{\mathrm{b}}\right)
$$

em que $j=1,2,3, \ldots, 52$ é o período semanal considerado para a semeadura; $\mathrm{Rs}_{\mathrm{j}}$ é a radiação solar global diária média para $\mathrm{o}$ período de sete dias; $\mathrm{Ta}_{\mathrm{j}}$ é a temperatura diária média do ar e 
$\mathrm{T}_{\mathrm{b}}=14{ }^{\circ} \mathrm{C}$ é a temperatura basal inferior para o algodoeiro. $\mathrm{O}$ coeficiente foto-térmico semanal foi utilizado no cálculo do índice de crescimento semanal (IC), através da expressão:

$$
(\mathrm{IC})_{\mathrm{j}}=(\mathrm{CF} . \mathrm{IT})_{\mathrm{j}}
$$

em que IT é um índice térmico derivado em função do efeito da temperatura do ar na taxa de crescimento relativo (TCR), obtido para o algodoeiro herbáceo segundo metodologia proposta por Wilson (1966), com valor mínimo de 0,25 para $\mathrm{T}_{\mathrm{b}}$ $=14^{\circ} \mathrm{C}$ e máximo de 1,0 para a temperatura na qual a cultura apresenta ótimo desenvolvimento, no caso $30^{\circ} \mathrm{C}$, decrescendo em seguida para alcançar 0,75 para a temperatura basal superior $\left(\mathrm{T}_{\mathrm{B}}=35^{\circ} \mathrm{C}\right)$.

Para uma estação de cultivo de 16 semanas, o potencial de rendimento da cultura, com base no período semanal de semeadura e nas condições climáticas locais, do ponto de vista da radiação solar e da temperatura, foi avaliado pelo índice acumulado de crescimento (IAC), obtido como:

$$
(\mathrm{IAC})_{\mathrm{j}}=\sum_{\mathrm{i}=\mathrm{j}}^{\mathrm{j}+15}\left[(\mathrm{IC})_{\mathrm{i}} \cdot \mathrm{CCV}_{\mathrm{i}}\right]
$$

Em que $\mathrm{CCV}_{\mathrm{i}}$ é o coeficiente de cobertura vegetal (relação entre a área de projeção da copa e a área máxima de superfície do solo ocupada por planta), a partir do período semanal de semeadura: $\mathrm{CCV}_{\mathrm{i}}=0,025$ a $0,025+\Delta \mathrm{CCV}_{\mathrm{i}}=0,025$ para $\mathrm{i}=$ $\mathrm{j}$ a $\mathrm{i}=\mathrm{j}+3 ; \mathrm{CCV}_{\mathrm{i}}=0,100$ a $0,100+\Delta \mathrm{CCV}_{\mathrm{i}}=0,125$ para $\mathrm{i}=\mathrm{j}+$ $4 \mathrm{a} \mathrm{i}=\mathrm{j}+7 \mathrm{CCV}_{\mathrm{i}}=0,600$ a $0,600+\Delta \mathrm{CCV}_{\mathrm{i}}=0,100$ para $\mathrm{i}=\mathrm{j}$ +8 a i $=j+11$ e $\mathrm{CCV}_{\mathrm{i}}=1,000$ a $1,000-\Delta \mathrm{CCV}_{\mathrm{i}}=0,075$ para $\mathrm{i}=\mathrm{j}+12 \mathrm{a} \mathrm{i}=\mathrm{j}+15$. Estes valores de $\mathrm{CCV}_{\mathrm{i}}$ foram obtidos para o algodoeiro herbáceo para a região de Sousa, PB (Azevedo \& Maciel, 1993; Azevedo et al., 2004). Com base nesta metodologia, a época de semeadura com menor risco climático para o cultivo do algodoeiro herbáceo ocorrerá quando o índice acumulado de crescimento atingir o valor máximo.

\section{b) Cultivos de sequeiro}

Em condições de fornecimento natural de água ao solo (regime de sequeiro), o risco climático para o cultivo do algodoeiro herbáceo foi determinado para todos estados da região Nordeste do Brasil, exceto o Maranhão, com disponibilidade de dados de precipitação pluviométrica e temperatura média do ar, com base na variação, a cada período semanal, do requerimento hídrico (RH) para estações de cultivo com início no período semanal de ordem $\mathrm{j}$, ou seja:

$$
(\mathrm{RH})_{\mathrm{j}}=\sum_{\mathrm{i}=\mathrm{j}}^{\mathrm{j}+15}\left(\mathrm{ET}_{\mathrm{p}}\right)_{\mathrm{i}} \cdot(\mathrm{CCH})_{\mathrm{i}}
$$

em que $\mathrm{ET}_{\mathrm{p}}$ é a evapotranspiração potencial semanal (milímetros para períodos de sete dias), obtida pelo método de Thornthwaite (1948). Na equação (4), (CCH) i é o consumo hídrico do período semanal i da estação de cultivo em relação ao período semanal de maior consumo, que assume os valores $\left(\mathrm{CCH}_{\mathrm{i}}=0,025 \mathrm{a}\right.$ $0,025+\Delta \mathrm{CCH}_{\mathrm{i}}=0,025$ para $\mathrm{i}=\mathrm{j}$ a $\mathrm{i}=\mathrm{j}+3 ; \mathrm{CCH}_{\mathrm{i}}=0,100 \mathrm{a}$ $0,100+\Delta \mathrm{CCH}_{\mathrm{i}}=0,200$ para $\mathrm{i}=\mathrm{j}+4 \mathrm{a} \mathrm{i}=\mathrm{j}+7 ; \mathrm{CCH}_{\mathrm{i}}=0,700 \mathrm{a}$ $0,700+\Delta \mathrm{CCH}_{\mathrm{i}}=0,075$ para $\mathrm{i}=\mathrm{j}+8 \mathrm{ai}=\mathrm{j}+11$ e $\mathrm{CCH}_{\mathrm{i}}=1,00$ a $1,000-\Delta \mathrm{CCH}_{\mathrm{i}}=0,125$ para $\mathrm{i}=\mathrm{j}+12 \mathrm{a} \mathrm{i}=\mathrm{j}+15$ ), obtidos por Azevedo et al. (2004). Com base nos valores semanais de $(\mathrm{RH})_{\mathrm{j}}$, foi calculado o déficit potencial de água (DPA) para a estação de cultivo com início no período semanal de ordem $\mathrm{j}$, pela expressão:

$$
(\text { DPA })_{j}=\sum_{i=j}^{i=j+15}\left(R_{i} / 2\right) \cdot p\left(P_{i} \leq R H_{i}\right)
$$

Em que i varia de $\mathrm{i}=\mathrm{j}$ a $\mathrm{i}=\mathrm{j}+15$ e $\mathrm{p}(\operatorname{Pr} \leq \mathrm{RH})_{\mathrm{i}}$ é a probabilidade da precipitação pluviométrica (Pr) ser menor ou igual ao requerimento hídrico para o período semanal i da estação de cultivo. O déficit potencial de água semanal (DPA) somente ocorrerá quando o requerimento hídrico semanal $(\mathrm{RH})_{\mathrm{i}}$ não for satisfeito pela precipitação, isto é, $\mathrm{RH}_{\mathrm{i}} \leq \mathrm{Pr}_{\mathrm{i}}$. Assim, para cultivos de sequeiro, o menor risco climático para qualquer época de semeadura do algodoeiro herbáceo ocorrerá quando o déficit potencial de água for mínimo.

O índice de déficit potencial de água (IDPA) foi definido como (Azevedo et al., 2004):

$$
(\mathrm{IDPA})_{\mathrm{j}}=10\left[\frac{\left(\mathrm{DPA}_{\mathrm{j}}-\mathrm{DPA}_{\mathrm{m}}\right)}{\left(\mathrm{DPA}_{\mathrm{x}}-\mathrm{DPA}_{\mathrm{m}}\right)}\right]
$$

em que os subscritos $\left({ }_{m}\right)$ e $\left(_{x}\right)$ referem-se, respectivamente, aos valores mínimo e máximo obtidos para o déficit potencial de água.

Na definição dos níveis de risco agro-climático, foram estabelecidas três classes, de acordo com o IDPA, assim especificadas:

$>$ Plenamente favorável ao cultivo (baixo risco): $0,0 \leq \mathrm{IDPA} \leq$ 0,1 ;

> Cultivo dependente de irrigação complementar (risco médio): $0,1 \leq \mathrm{IDPA} \leq 0,2$;

$>$ Desfavorável ao cultivo (alto risco): IDPA $>0,2$.

$\mathrm{Na}$ espacialização do IDPA foi utilizado o software Surfer, versão 7.0, para obtenção de mapas do zoneamento do grau de risco agro-climático para cada época de semeadura semanal. Foram então, elaborados 52 mapas da região Nordeste do Brasil, contendo a variação espacial das classes de risco climático para cada época de semeadura (semana do ano).

Na geração da grade regular, foi escolhido o interpolador do Surfer que interpola seguindo o critério do inverso da distância ao ponto, o qual mais se aproxima das condições de linearidade, já que se trata basicamente de uma análise bidimensional, na qual os valores do IPDA são espacializados em função do tempo, sendo desprezadas as condições de 
relevo. Assim, foi selecionado o interpolador que considera a média dos $\mathrm{n}$ pontos mais próximos por quadrante de grade regular, com peso $\mathrm{Wi}=1 / \mathrm{d}^{\mathrm{n}}, \mathrm{i}=1,2,3 \ldots ., \mathrm{n}$; e d = distância Euclidiana do i-ésimo ponto amostrado ao ponto interpolado e $\mathrm{n}=$ expoente da função distância. Com esse método foi possível contemplar as localidades que não dispunham de dados suficientes ao zoneamento, pois o software utilizado interpola os resultados obtidos das localidades vizinhas com disponibilidade de dados, para aquelas com dados insuficientes, antes não contempladas.

\section{RESULTADOS E DISCUSSÕES}

A maioria dos municípios da região Nordeste do Brasil não dispõe de dados de radiação solar. Assim, para condições de irrigação, o nível de risco climático foi determinado apenas para algumas localidades situadas em perímetros irrigados:
Sousa-PB, Petrolina-PE, Morada Nova-CE, Mossoró-RN, os quais são representativos das áreas com potencial hidro-edáfico para o cultivo irrigado do algodoeiro. Os resultados indicaram que a época de semeadura do algodoeiro herbáceo com menor risco climático nessas localidades ocorre nos períodos semanais de 6 à 17 de agosto (IAC $\approx 3,03)$.

Para cultivos de sequeiro, os valores do índice de déficit potencial de água (IDPA) e do período semanal de semeadura (PS) para localidades com condições plenamente favoráveis (baixo risco); cultivo dependente de irrigação complementar (risco médio) e desfavorável (alto risco) ao cultivo do algodoeiro herbáceo de cada estado da região Nordeste do Brasil são apresentados na Tabela 1. Os valores do IDPA, para estações de cultivo com início em cada semana do ano, foram utilizados na confecção dos 52 mapas de zoneamento do risco climático para o cultivo do algodoeiro herbáceo para as localidades dos estados do Nordeste.

Tabela 1 - Índice de déficit potencial de água (IDPA) e período de semeadura (PS) para localidades com condições plenamente favoráveis ao cultivo (baixo risco), cultivo dependente de irrigação complementar (risco médio) e desfavorável (alto risco) ao cultivo do algodão herbáceo nos estado da região Nordeste do Brasil

\begin{tabular}{|c|c|c|c|c|c|}
\hline ESTADO/MUNICÍPIO & LAT (S) & LONG (W) & ALT (m) & IDPA & PS \\
\hline \multicolumn{6}{|l|}{ Alagoas } \\
\hline Quebrangulo (baixo risco) & $9^{\circ} 20^{\prime}$ & $36^{\circ} 29^{\prime}$ & 411 & 0,00 & 09 a $22 / 04$ \\
\hline São José do Lage (risco médio) & $9^{\circ} 01^{\prime}$ & $36^{\circ} 03^{\prime}$ & 250 & 0,14 & $30 / 04$ a $13 / 05$ \\
\hline Craíba (alto risco) & $9^{\circ} 37^{\prime}$ & $36^{\circ} 47^{\prime}$ & 230 & 2,13 & 02 a 22/04 \\
\hline \multicolumn{6}{|l|}{ Bahia } \\
\hline Senhor do Bonfim (baixo risco) & $10^{\circ} 28^{\prime}$ & $40^{\circ} 11^{\prime}$ & 544 & 0,00 & 05 a $18 / 03$ \\
\hline Rui Barbosa (risco médio) & $12^{\circ} 17^{\prime}$ & $40^{\circ} 27^{\prime}$ & 395 & 0,15 & $19 / 02$ a $04 / 03$ \\
\hline Formosa do Rio Preto (alto risco) & $11^{\circ} 03^{\prime}$ & $45^{\circ} 12^{\prime}$ & 491 & 3,76 & 05 a $11 / 11$ \\
\hline \multicolumn{6}{|l|}{ Ceará } \\
\hline Meruoca (baixo risco) & $3^{\circ} 27^{\prime}$ & $40^{\circ} 29^{\prime}$ & 450 & 0,00 & $22 / 01$ a $04 / 02$ \\
\hline Tamboril (risco médio) & $4^{\circ} 50^{\prime}$ & $40^{\circ} 20^{\prime}$ & 360 & 0,12 & $22 / 01$ a $04 / 02$ \\
\hline Guaiúba (alto risco) & $4^{\circ} 02^{\prime}$ & $38^{\circ} 38^{\prime}$ & 59 & 0,58 & 12 a $25 / 02$ \\
\hline \multicolumn{6}{|l|}{ Paraíba } \\
\hline Souza (baixo risco risco) & $6^{\circ} 45^{\prime}$ & $38^{\circ} 14^{\prime}$ & 200 & 0,00 & $29 / 01$ a $11 / 02$ \\
\hline Desterro (risco médio) & $7^{\circ} 17^{\prime}$ & $37^{\circ} 06^{\prime}$ & 590 & 0,12 & 05 a $25 / 02$ \\
\hline Serraria (alto risco) & $6^{\circ} 49^{\prime}$ & $35^{\circ} 38^{\prime}$ & 360 & 2,57 & 02 a $15 / 04$ \\
\hline \multicolumn{6}{|l|}{ Pernambuco } \\
\hline Cortês (baixo risco) & $8^{\circ} 28^{\prime}$ & $35^{\circ} 33^{\prime}$ & 340 & 0,00 & 12 a $25 / 03$ \\
\hline Barra de Guabiraba (risco médio) & $8^{\circ} 25^{\prime}$ & $35^{\circ} 40^{\prime}$ & 440 & 0,17 & 09 a $22 / 04$ \\
\hline Petrolina (alto risco) & $9^{\circ} 23^{\prime}$ & $40^{\circ} 30^{\prime}$ & 376 & 4,41 & 05 a $18 / 02$ \\
\hline \multicolumn{6}{|l|}{ Piauí } \\
\hline Campo Maior (baixo risco) & $4^{\circ} 49^{\prime}$ & $42^{\circ} 11^{\prime}$ & 125 & 0,00 & 15 a $28 / 01$ \\
\hline Valência do Piauí (risco médio) & $6^{\circ} 24^{\prime}$ & $41^{\circ} 45^{\prime}$ & 295 & 0,20 & 15 a $28 / 01$ \\
\hline Oeiras (alto risco) & $7^{\circ} 01^{\prime}$ & $42^{\circ} 08^{\prime}$ & 170 & 0,22 & 01 a $14 / 01$ \\
\hline \multicolumn{6}{|l|}{ Rio Grande do Norte } \\
\hline Mossoró (menor risco) & $5^{\circ} 12^{\prime}$ & $37^{\circ} 21^{\prime}$ & 015 & 0,01 & 05 à $25 / 02$ \\
\hline Apodi (baixo risco) & $5^{\circ} 40^{\prime}$ & $37^{\circ} 48^{\prime}$ & 305 & 0,12 & 05 à 25/02 \\
\hline Pureza (alto risco) & $5^{\circ} 32^{\prime}$ & $35^{\circ} 32^{\prime}$ & 060 & 2,05 & $12 / 03$ à $01 / 04$ \\
\hline \multicolumn{6}{|l|}{ Sergipe } \\
\hline Barra de Guabiraba (baixo risco) & $8^{\circ} 25^{\prime}$ & $35^{\circ} 40^{\prime}$ & 440 & 0,00 & 09 a $22 / 04$ \\
\hline Estância (risco médio) & $11^{\circ} 16^{\prime}$ & $37^{\circ} 27^{\prime}$ & 053 & 0,11 & 16 a $29 / 04$ \\
\hline Cumbe (alto risco) & $10^{\circ} 29^{\prime}$ & $37^{\circ} 14^{\prime}$ & 180 & 0,27 & 16 a $29 / 04$ \\
\hline
\end{tabular}




\section{1) Avaliação por Estado da Região}

- Alagoas

O período semanal com menor risco climático à semeadura do algodoeiro herbáceo no estado de Alagoas ocorre no período compreendido entre a $13^{\mathrm{a}}$ ( 26 de março a 01 de abril) e a $19^{\text {a }}$ (07 a 13 de maio) semana do ano. As demais semanas mostraram-se totalmente desfavoráveis à semeadura para todas as localidades do estado. Este período favorável à semeadura se concentra no período compreendido entre a $15^{\text {a }}(09$ à 15 de abril) e a $17^{\text {a }}$ (23 a 29 de abril) semana do ano, com máxima cobertura na $16^{\mathrm{a}}$ semana do ano (16 à 22 de abril - Figura 1) quando as condições favoráveis à semeadura ocorrem em todas as áreas do estado.

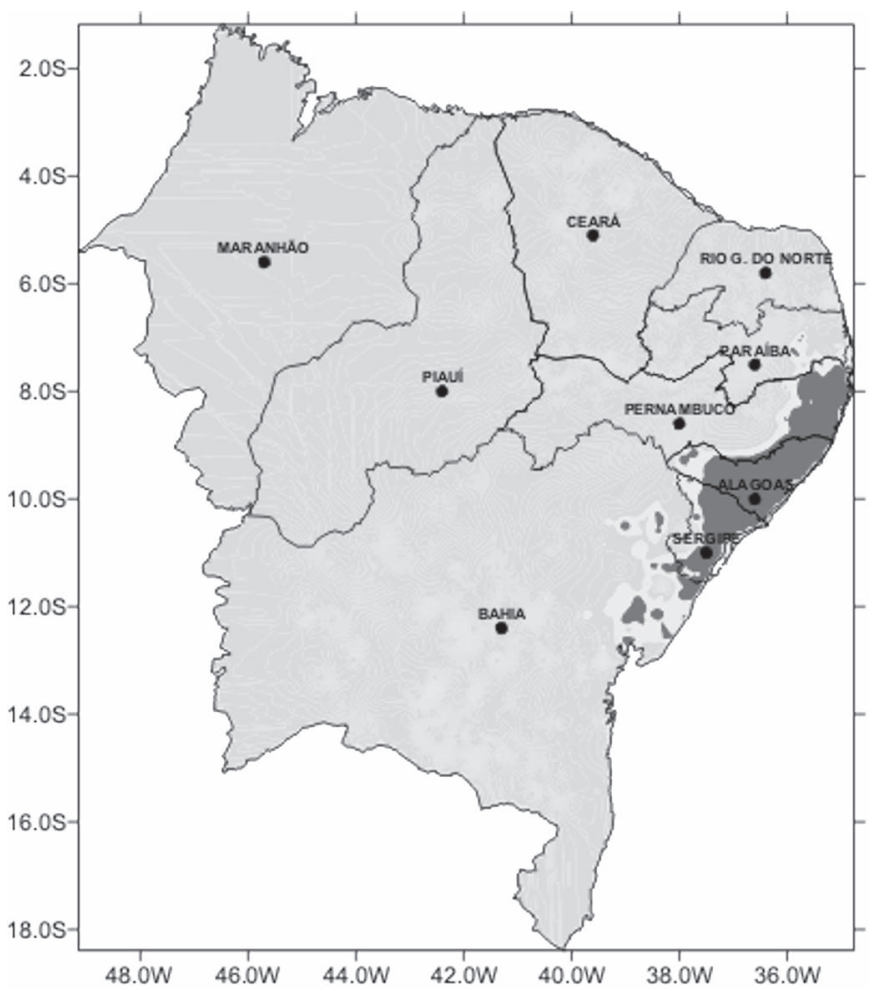

Figura 1 - Áreas da Região Nordeste com condições: Favoráveis $(\bullet)$, Intermediárias $(\bullet)$ e Desfavoráveis $(\bullet)$ à semeadura do algodoeiro herbáceo na $16^{\mathrm{a}}$ semana do ano (16 à 22 de abril)

- Bahia

O período semanal com menor risco climático à semeadura do algodoeiro herbáceo no estado da Bahia ocorre no período compreendido entre a $44^{\text {a }}$ ( 29 de outubro a 04 de novembro) e a $18^{\mathrm{a}}$ (30 de abril a 06 de maio) semana do ano. As demais semanas mostraram-se totalmente desfavoráveis à semeadura para todas as localidades do estado. Para o estado da Bahia, o cultivo do algodoeiro herbáceo é recomendado em quatro momentos distintos ao longo do ano. O primeiro momento (região CentroNorte) compreende o período de semeadura entre a $1^{\mathrm{a}}$ e a $5^{\mathrm{a}}$ semana do ano (01 de janeiro a 04 de fevereiro), com máxima cobertura na $3^{\mathrm{a}}$ semana do ano (15 à 21 de janeiro - Figura 2). $\mathrm{O}$ segundo momento (faixa Norte-Sul entre os meridianos de $39^{\circ}$ e $41^{\circ} \mathrm{W}$ ) compreende o período de semeadura entre a $7^{\mathrm{a}}$ e a $12^{\mathrm{a}}$ semana do ano (12 de fevereiro a 25 de março), com máxima cobertura na $10^{\mathrm{a}}$ semana do ano (05 à 11 de março - Figura 3). O terceiro momento (região Litoral-Central) compreende o período de semeadura entre a $13^{\mathrm{a}}$ e a $16^{\mathrm{a}}$ semanas do ano, com máxima cobertura na $14^{\mathrm{a}}$ semana do ano (02 à 08 de abril - Figura 4). O quarto momento (região Oeste) compreende o período de semeadura entre a $45^{\text {a }}$ e a $49^{\mathrm{a}}$ semana do ano ( 05 de novembro a 09 de dezembro), com máxima cobertura na $46^{\mathrm{a}}$ semana do ano (12 à 18 de novembro - Figura 5).

\section{- Ceará}

O período semanal com menor risco climático à semeadura do algodoeiro herbáceo no estado do Ceará ocorre entre a $3^{\text {a }}$ ( 15 a 21 de janeiro) e a $10^{\text {a }}$ ( 05 a 11 de março) semana do ano. As demais semanas mostraram-se totalmente desfavoráveis à semeadura para todas as localidades do estado. Os resultados evidenciam também, que a adequação da semeadura para baixo e médio risco climático ocorre inicialmente, na região Sul na $3^{\mathrm{a}}$ semana do ano (15 a 21 de janeiro), evoluindo para toda a faixa Oeste do estado nas $4^{\mathrm{a}}$ e $5^{\mathrm{a}}$ semana do ano (22 de janeiro a 04 de fevereiro), cobrindo todo o estado, exceto a região Sul na $6^{\mathrm{a}}$ semana do ano (05 a 11 de fevereiro - Figura 6). A partir de então, as condições mais favoráveis avançam na direção das regiões Centro Este e Nordeste do estado nas $7^{\mathrm{a}}$ e $8^{\mathrm{a}}$ semanas do ano (12 a 25 de fevereiro), diminuindo em seguida para desaparecerem totalmente a partir da $11^{\mathrm{a}}$ semana do ano (12 a 18 de março).

\section{- Paraíba}

O período semanal com menor risco climático à semeadura do algodoeiro herbáceo no estado da Paraíba ocorre entre a $4^{\text {a }}$ (22 a 28 de janeiro) e a $17^{\text {a }}$ (23 a 29 de Abril) semana do ano. As demais semanas mostram-se totalmente desfavoráveis (alto risco) à semeadura para todas as localidades do Estado. A adequação da semeadura ocorre inicialmente, na metade Oeste, com máxima cobertura dessas áreas na $6^{\mathrm{a}}$ semana do ano (05 a 11 de Fevereiro - Figura 6). A partir dessa data, a área de cobertura se reduz ao longo do tempo para alcançar poucas localidades da região Seridó na $9^{\text {a }}$ semana do ano ( 26 de fevereiro a 04 de março). A partir da $10^{\mathrm{a}}$ semana do ano (05 a 12 de Março), a época de semeadura do algodoeiro herbáceo avança em direção à Costa Este do estado, alcançando maior área de cobertura na $14^{\mathrm{a}}$ semana do ano (02 a 08 de abril - Figura 4), reduzindo-se, em seguida para atingir apenas os municípios de Areia e Alagoa Nova na região do Brejo paraibano, na $17^{\mathrm{a}}$ semana do ano (23 a 29 de abril) - Azevedo et al. (2004). 


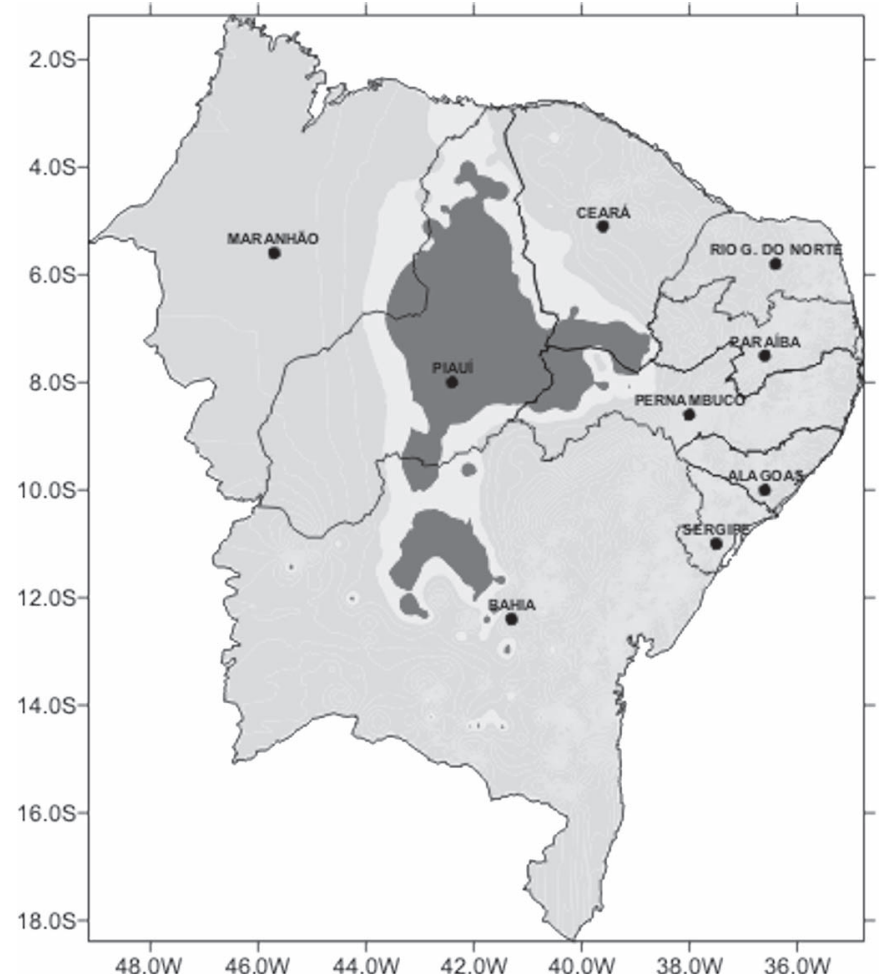

Figura 2 - Áreas da Região Nordeste com condições: Favoráveis $(\bullet)$, Intermediárias $\left({ }^{\circ}\right)$ e Desfavoráveis $(\bullet)$ à semeadura do algodoeiro herbáceo na $3^{\mathrm{a}}$ semana do ano (15 à 21 de janeiro)

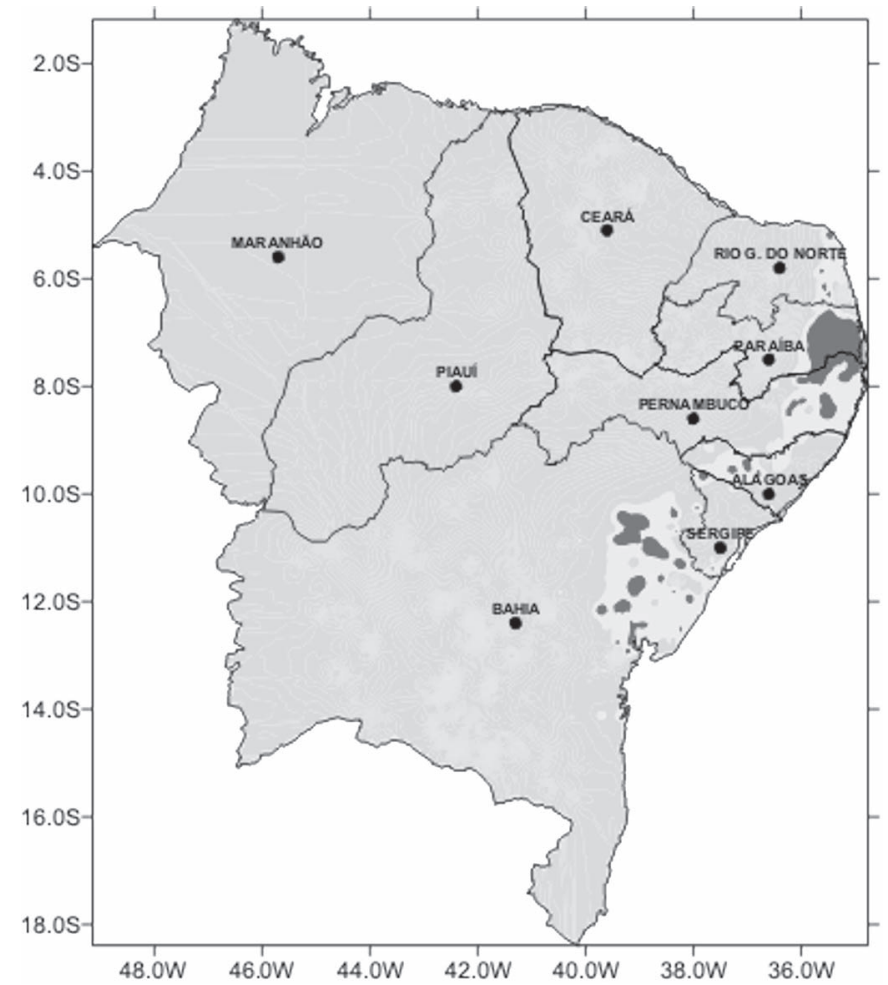

Figura 4 - Áreas da Região Nordeste com condições: Favoráveis $(\bullet)$, Intermediárias $\left({ }^{\circ}\right)$ e Desfavoráveis $(\bullet)$ à semeadura do algodoeiro herbáceo na $14^{\mathrm{a}}$ semana do ano (02 à 08 de abril)

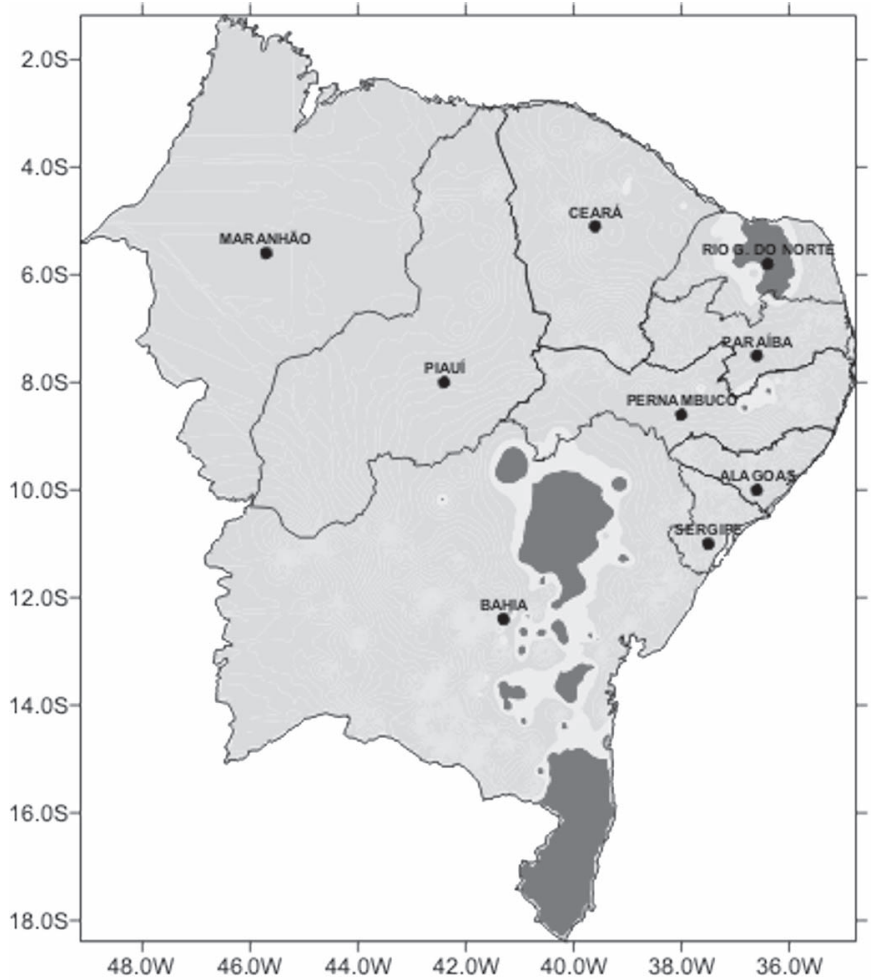

Figura 3 - Áreas da Região Nordeste com condições: Favoráveis $(\bullet)$, Intermediárias $\left({ }^{\circ}\right)$ e Desfavoráveis $(\bullet)$ à semeadura do algodoeiro herbáceo na $10^{\mathrm{a}}$ semana do ano (05 à 11 de março)

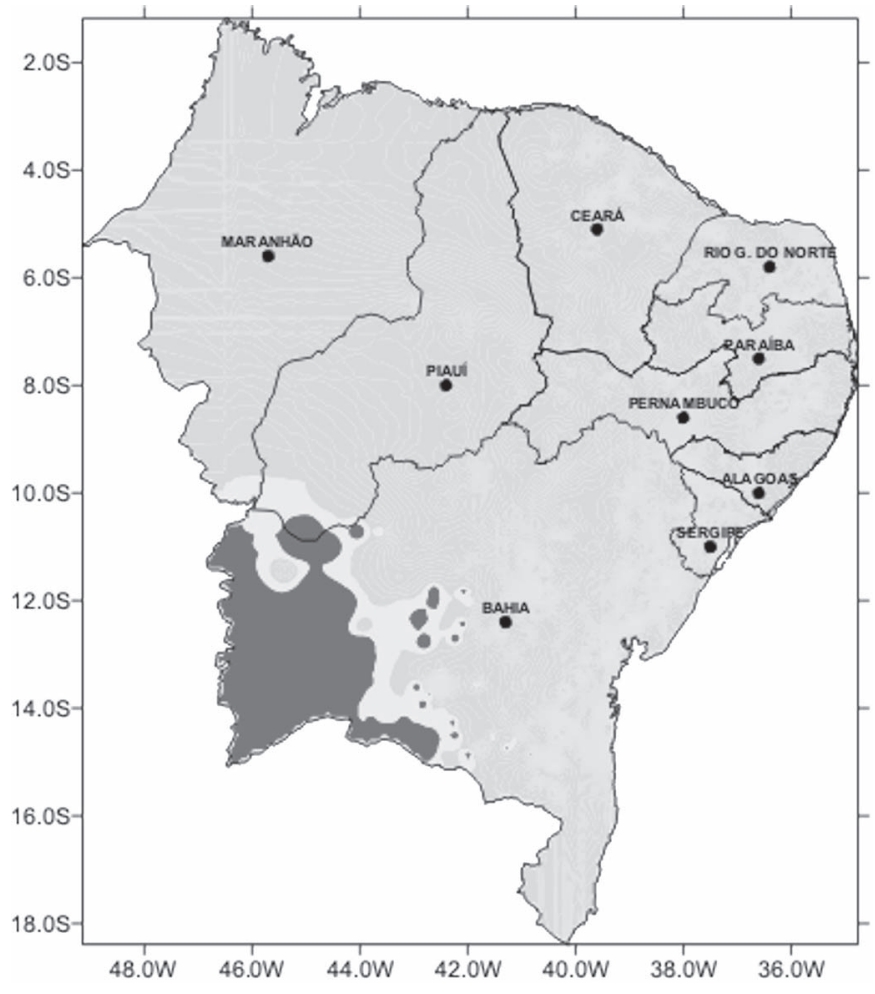

Figura 5 - Áreas da Região Nordeste com condições: Favoráveis $(\bullet)$, Intermediárias $(\bullet)$ e Desfavoráveis $(\bullet)$ à semeadura do algodoeiro herbáceo na $46^{\mathrm{a}}$ semana do ano (12 à 18 de novembro) 


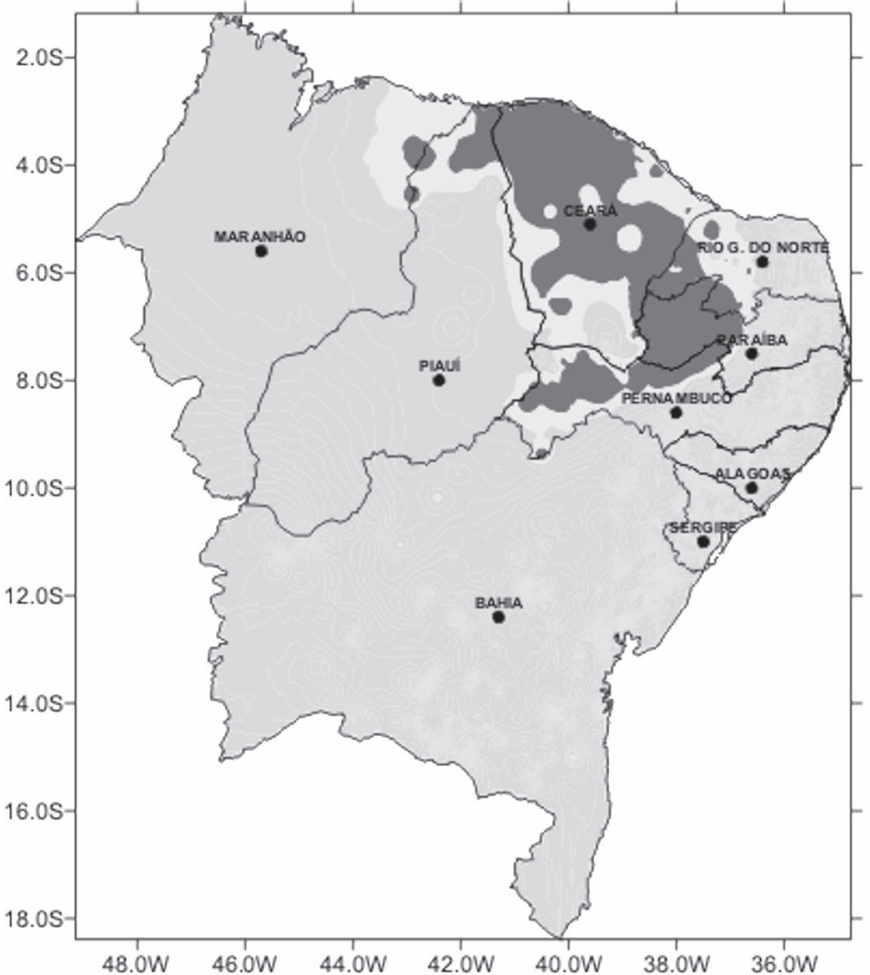

Figura 6 - Áreas da Região Nordeste com condições: Favoráveis $(\bullet)$, Intermediárias $(\bullet)$ e Desfavoráveis $(\bullet)$ à semeadura do algodoeiro herbáceo na $6^{\mathrm{a}}$ semana do ano (05 à 11 de fevereiro)

\section{- Pernambuco}

O período semanal com menor risco climático à semeadura do algodoeiro herbáceo no estado da Pernambuco ocorre no período compreendido entre a $2^{\mathrm{a}}(08$ a 14 de janeiro - região Oeste do Estado) e a $19^{\text {a }}$ (07 a 13 de maio - região Este do estado) semana do ano. As demais semanas mostraram-se totalmente desfavoráveis à semeadura para todas as localidades do estado. Observa-se que a época de semeadura do algodoeiro herbáceo no estado de Pernambuco ocorre inicialmente na metade Oeste e depois na metade Este do estado. A época de semeadura alcança maior área da metade Oeste do estado na $6^{\mathrm{a}}$ semana do ano (05 à 11 de fevereiro - Figura 6). A partir dessa data, a área de cobertura se reduz ao longo do tempo para alcançar poucas localidades da região Central na $11^{\mathrm{a}}$ semana do ano (12 à 18 de março). A partir da $12^{\mathrm{a}}$ semana do ano (19 à 25 de Março), a época de semeadura do algodoeiro herbáceo avança em direção à Costa Este do estado, alcançando maior área de cobertura na $15^{\mathrm{a}}$ semana do ano (09 à 15 de abril - Figura 7), reduzindo-se, em seguida para atingir apenas poucos municípios, nas $18^{\mathrm{a}} \mathrm{e}$ $19^{\mathrm{a}}$ semanas do ano (30 de abril a 13 de maio).

- Piauí

O período semanal com menor risco climático à semeadura do algodoeiro herbáceo no estado do Piauí ocorre entre a

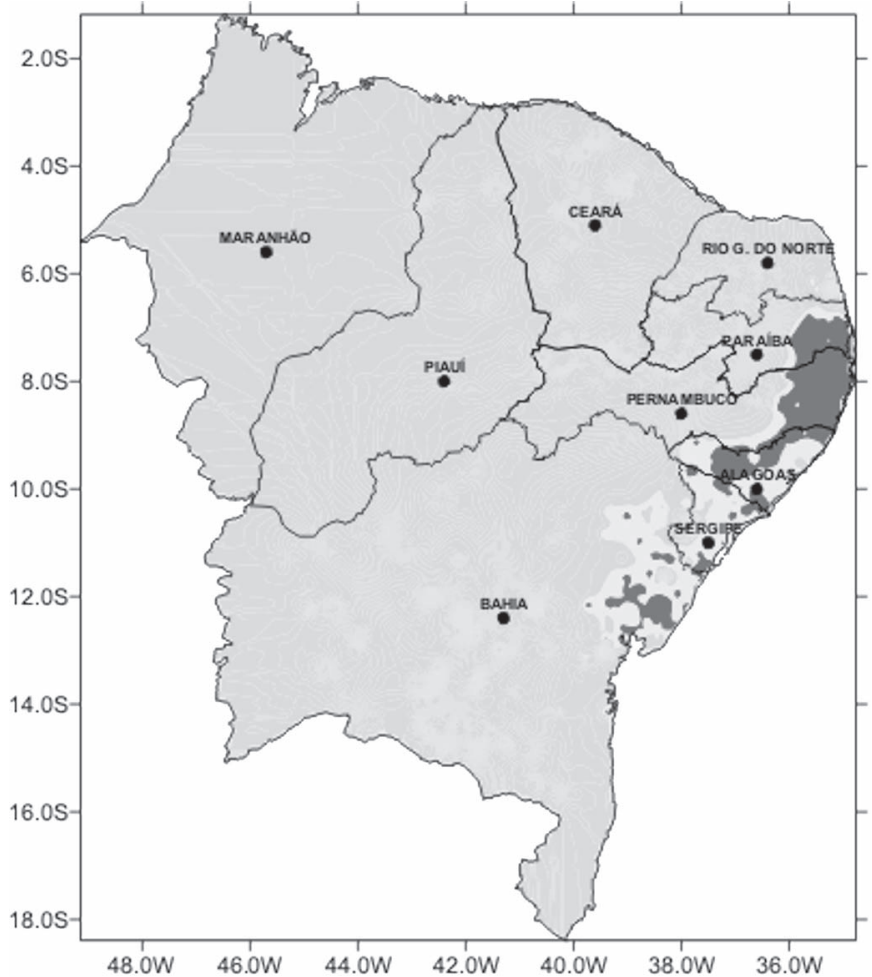

Figura 7 - Áreas da Região Nordeste com condições: Favoráveis $(\bullet)$, Intermediárias $(\bullet)$ e Desfavoráveis $(\bullet)$ à semeadura do algodoeiro herbáceo na $15^{\mathrm{a}}$ semana do ano (09 à 15 de abril)

$1^{\mathrm{a}}$ (01 à 07 de janeiro - região Oeste do estado) e a $7^{\mathrm{a}}$ (12 à 18 de fevereiro) semana do ano. As demais semanas mostraram-se totalmente desfavoráveis à semeadura para todas as localidades do estado. As condições favoráveis ao cultivo do algodoeiro se iniciam na parte Central do estado logo na primeira semana do ano (01 à 07 de janeiro), intensificando-se a partir da $2^{\mathrm{a}}$ semana do ano (08 à 14 de janeiro). A partir de então, avançam nas direções Norte e Sul, cobrindo a maior parte do estado na $3^{\mathrm{a}}$ semanas do ano (15 à 21 de janeiro - Figuras 2). A partir da $8^{\mathrm{a}}$ semana do ano (19 à 25 de fevereiro), todas as localidades do estado apresentam condições desfavoráveis à semeadura do algodão herbáceo.

\section{- Rio Grande do Norte}

$\mathrm{O}$ período semanal com menor risco climático à semeadura do algodoeiro herbáceo no estado do Rio Grande do Norte ocorre no período compreendido entre a $5^{\text {a }}(29$ de janeiro a 04 de fevereiro) e a $15^{\text {a }}$ (09 à 15 de abril) semana do ano. As demais semanas mostraram-se totalmente desfavoráveis à semeadura para todas as localidades do estado. Observa-se ainda que a época de semeadura do algodoeiro herbáceo com baixo e médio risco climático no estado do Rio Grande do Norte segue os mesmos padrões do que foi observado para os estados da Paraíba e Pernambuco, ou seja, 
ocorre inicialmente na metade Oeste e depois na metade Este do estado. A época de semeadura com menor risco climático inicia-se na $5^{\mathrm{a}}$ semana, alcançando as maiores áreas da metade Oeste do estado nas $6^{\mathrm{a}}$ e $7^{\mathrm{a}}$ semanas do ano (05 à 18 de fevereiro - Figuras 6). Da $8^{\mathrm{a}}$ à $11^{\mathrm{a}}$ semanas do ano, a área de cobertura se intensifica em toda região Central do estado, com destaque para a $10^{\mathrm{a}}$ semana do ano (05 à 11 de março - Figura 3). A partir da $12^{\mathrm{a}}$ semana do ano (19 à 25 de Março), a época de semeadura do algodoeiro herbáceo avança em direção à Costa Este do estado, alcançando maior área de cobertura na $13^{\mathrm{a}}$ semana do ano (26 de março a 01 de abril - Figura 8), reduzindo-se, em seguida para atingir apenas algumas localidades, na $14^{\mathrm{a}}$ semana do ano (02 à 15 de abril - Figura 4).

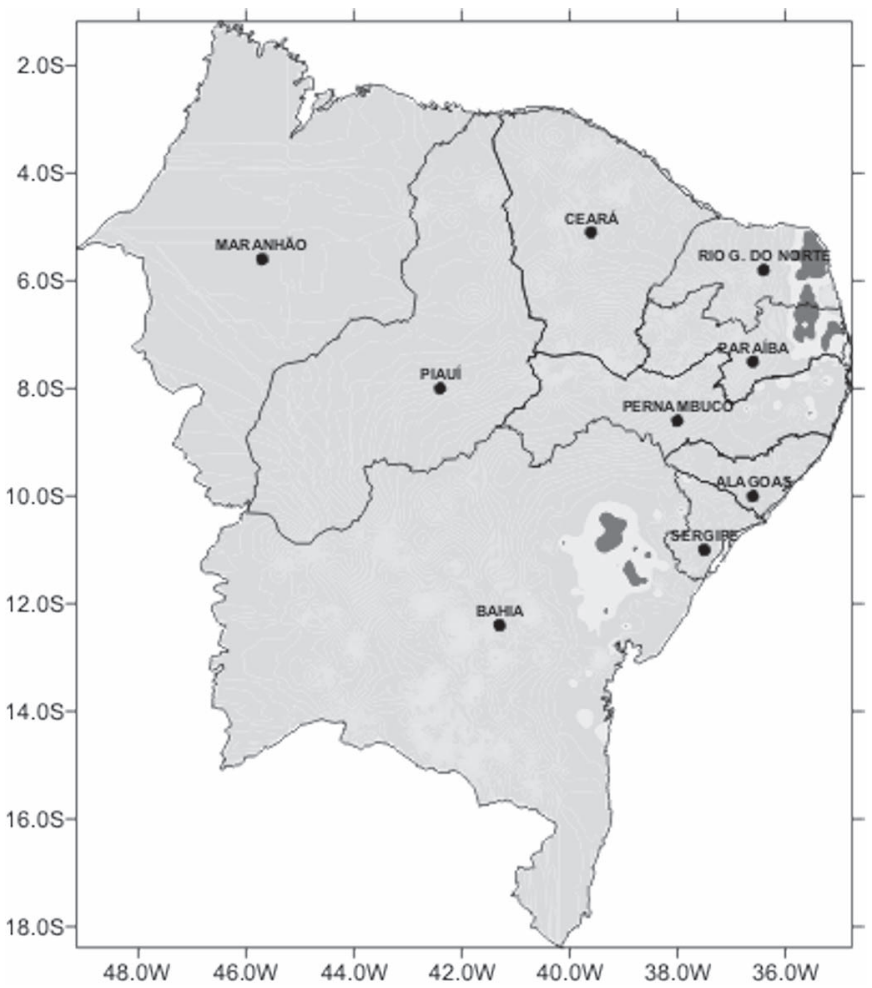

Figura 8 - Áreas da Região Nordeste com condições: Favoráveis $(\bullet)$, Intermediárias $(\bullet)$ e Desfavoráveis $(\bullet)$ à semeadura do algodoeiro herbáceo na $13^{\mathrm{a}}$ semana do ano (26 de março a 01 de abril)

\section{- Sergipe}

O período semanal com menor risco climático à semeadura do algodoeiro herbáceo no estado de Sergipe ocorre no período compreendido entre a $12^{\mathrm{a}}$ (19 à 25 de março) e a $19^{\mathrm{a}}(07$ à 13 de maio) semana do ano. As demais semanas mostraram-se totalmente desfavoráveis à semeadura para todas as localidades do estado. O período favorável à semeadura, com baixo e médio risco climático, concentra-se na $16^{\mathbf{a}}$ semana do ano (16 à 22 de abril - Figura 1).

\section{2) Avaliação para toda a Região}

Em geral, o cultivo do algodão herbáceo na região Nordeste do Brasil, com baixo e médio risco climático, compreende a semeadura desde a $44^{\mathrm{a}}$ ( 29 de outubro e 04 de novembro) até a $19^{\mathrm{a}}$ (07 à 14 de maio) semana do ano. Assim, a época de semeadura do algodão herbáceo com baixo risco climático na região Nordeste inicia-se na região Oeste da Bahia na $44^{\mathrm{a}}$ semana do ano (29 de outubro a 04 de novembro), alcançando um máximo na $46^{\mathrm{a}}$ semana do ano (12 à 18 de novembro - Figura 5). Para a $1^{\mathrm{a}}$ semana do ano (01 à 07 de janeiro), as condições favoráveis à semeadura do algodoeiro herbáceo se iniciam na região Central do Piauí (Figura 2). O máximo de aptidão ocorre da $4^{\mathrm{a}}$ à $8^{\mathrm{a}}$ semana do ano (22 de janeiro a 25 de fevereiro), pois é neste período que o algodoeiro encontra condições favoráveis à semeadura na maior parte dos estados do Piauí, Rio Grande do Norte, Paraíba, Pernambuco e norte da Bahia. A região Sul da Bahia apresenta condições favoráveis à semeadura do algodoeiro com menor risco climático apenas na $10^{\mathrm{a}}$ semana do ano (05 à 11 de março - Figura 3). Da $12^{\mathrm{a}}$ à $19^{\mathrm{a}}$ semana do ano, as áreas da região do Nordeste do Brasil mais favoráveis ao cultivo do algodoeiro herbáceo estão situadas na Costa Leste e áreas litorâneas, sendo o período que vai da $14^{\mathrm{a}}$ à $17^{\mathrm{a}}$ semanas do ano (02 à 29 de abril), o de maior área de abrangência, pois envolve desde o Litoral de Pernambuco até o Litoral Norte do estado da Bahia, envolvendo quase que totalmente os estados de Alagoas e Sergipe (Figura 1). Resultados semelhantes foram encontrados por Amorim Neto et al. (1997).

\section{CONCLUSÕES}

a) O cultivo do algodoeiro na região Nordeste do Brasil pode ser efetuado com baixo e médio risco climático, desde que a semeadura ocorra no período compreendido entre a $44^{\mathrm{a}}$ (29 de outubro e 04 de novembro - região Oeste da Bahia) a $17^{\text {a }}$ semana do ano (23 a 29 de abril - Litoral dos estados de Pernambuco, Alagoas e Sergipe);

b) A partir da $1^{\text {a }}$ semana do ano (01 à 07 de janeiro), as condições favoráveis à semeadura do algodoeiro se iniciam na região Central do Piauí, alcançando maior área de cobertura no período entre a $4^{\mathrm{a}}$ e a $8^{\mathrm{a}}$ semana do ano ( 22 de janeiro a 25 de fevereiro), quando o algodoeiro encontra condições favoráveis a semeadura no Norte do Piauí, Ceará, Oeste dos estados Rio Grande do Norte, Paraíba, Pernambuco e Norte da Bahia.

c) As regiões Sul e Oeste do estado da Bahia apresentam condições favoráveis à semeadura do algodoeiro apenas na $10^{\mathrm{a}}$ semana do ano (05 à 11 de março) e entre a $45^{\mathrm{a}}$ e a $49^{\mathrm{a}}$ semana do ano (05 de novembro a 09 de dezembro), com máxima cobertura na $46^{\mathrm{a}}$ semana do ano (12 à 18 de novembro), respectivamente; 
d) Na Costa Leste e áreas litorâneas da região do Nordeste do Brasil, a semeadura do algodoeiro herbáceo é mais favorável no período compreendido entre a $14^{\mathrm{a}}$ e a $17^{\mathrm{a}}$ semana do ano (02 à 29 de abril), com maior área de abrangência na $16^{a}$ semana do ano (16 a 22 de abril), pois envolve as áreas litorâneas do Rio Grande do Norte ao Norte do estado da Bahia, além da quase que totalmente os estados de Alagoas e Sergipe.

\section{AGRADECIMENTOS}

O presente trabalho foi parcialmente financiado pelo Conselho Nacional de Pesquisa Científica e Tecnológica - CNPq, através de bolsas de Produtividade em Pesquisa e de PIBIC. Os autores agradecem ao Departamento de Ciências Atmosféricas do Centro de Tecnologia e Recursos Naturais da Universidade Federal de Campina Grande pela concessão dos dados utilizados e às facilidades computacionais.

\section{REFERÊNCIAS BIBLIOGRÁFICAS}

AMORIM NETO, M. S. \& BELTRÃO N. E. M. Determinação da época de irrigação em algodoeiro herbáceo por via climatológica. Embrapa Algodão, Campina Grande-PB, Comunicado Técnico, 34, 17p. 1992.

AMORIM NETO, M. S.; MEDEIROS, J. C.; BELTRÃO, N. E. M.; FREIRE, E. C.; NOVAES FILHO, M. B. \& GOMES, D. C. Zoneamento do algodoeiro herbáceo para o Nordeste brasileiro. Congresso Brasileiro de Algodão, I, Fortaleza-CE. Anais, ..., p. 35 - 37, 1997.

AZEVEDO, P. V. de \& MACIEL, G. F. Estação de cultivo e época de semeadura para o algodão herbáceo na região de Sousa-PB. Revista Brasileira de Agrometeorologia, Santa Maria-RS, v. 1, n. 1, p. 81-85, 1993.

AZEVEDO, P.V. DE; SANTOS SILVA, F.D. dos; BEZERRA, J.R.C. Zoneamento da época de semeadura do algodoeiro herbáceo no estado da Paraíba. Revista Brasileira de Agrometeorologia, Piracicaba-SP, v.12, n.2, p. 379-386, 2004.

BARRETO, A. N.; BELTRÃO, N. E. M.; BEZERRA, J. R. C. \& LUZ, M. J. S. Configuração de plantio na cultura do algodoeiro herbáceo irrigado por sulcos. Campina Grande-PB: EMBRAPA-CNPA, 1994. 7p. (EMBRAPACNPA. Pesquisa em andamento, 18).
BASTOS, E. J. de B. \& AZEVEDO, P. V. Delimitação dos regimes de precipitação no estado da Paraíba. In: Congresso Brasileiro de Meteorologia, IV e Congresso Interamericano de Meteorologia, I, Brasília-DF. Anais, ..., v. 1, p. 129 - 134, 1986.

CHAVES, I. B.; FREIRE, O. \& AMORIM NETO, M. S. Características da precipitação e riscos de erosão na região tropical semi-árida brasileira. Pesquisa Agropecuária Brasileira, Brasília-DF, v. 20, n. 9, p. 991 - 998, 1982.

FALLIERI, J. \& SILVA, A. Ensaio de épocas de plantio do algodoeiro na Estação Experimental de Sete Lagoas, MG. IPEACO, 9p., 1968.

FEDERACION NACIONAL DE ALGODONEROS. Bases técnicas para el cultivo del algodón em Colombia. Bogotá, 714p., 1990.

GARGANTINI, P.E.; HERnANDEZ, F.B.T. A Cidade: Desenvolvendo com a Agricultura Irrigada e o Agronegócio. Ribeirão Preto: 2003.3p.

LACA-BUENDIA, J. P.; OLIVEIRA, P. de; PIRES, G. A. D. \& SILVA FILHO, P. V. Estudo de época de plantio $\mathrm{x}$ cultivares de algodão herbáceo (Gossypium hirsutum L. var. latifolium Hutch) nas principais regiões algodoeiras de Minas Gerais. In: EPAMIG (Belo Horizonte, MG). Projeto Algodão, Relatório 1980/92. p. 594 - 596, 1997.

SANTOS, A.R. dos. Zoneamento agroclimático para a cultura do café conilon (Coffea canephora $L$.) e arábica (Coffea arabica L.), na bacia do Itapemirim, ES. Viçosa: UFV, 1999. 59p. Tese Mestrado.

SEDIYAMA, G.C.; MELO Jr., J.C.F.; SANTOS, A.R.; RIBEIRO, A.; COSTA, M.H.; HAMAKAWA, P.J.; COSTA, J.M.N.; COSTA, L.C. Zoneamento agroclimático do cafeeiro (Coffea arábica L.) para o estado de Minas Gerais. Revista Brasileira de Agrometeorologia, v. 9, n. 3, p.501-509, 2001.

STEENKAMP, C. J. \& KOCK, H. de. Cost of production: Short season vs conventional cotton. In: International Cotton Advisory Committee: Short season cotton: how for can it go? Tashkent, Uzbekistan, Technical Seminar at the 55th Plenary Meeting of the ICAC, p. 25 - 27, 1996.

WORLD BANK. Irrigation and dreanage research, v. 1, 21p., 1990. 